\title{
Bending and Torsional Characteristics of Carbon Fiber and Balsa Wood Sandwich Composite
}

\author{
Astasari $^{1}$, Sutikno $^{1}$, and Wahyu Wijanarko ${ }^{1}$
}

\begin{abstract}
Bending properties and torsional stiffness of carbon fiber woven and balsa wood sandwich composites are studied and presented in this paper. Three point bending and torsional responses are tested with finite element's software. The finite element method was employed to determine applied load, total deformation, and equivalent stress of sandwich beam with different number of carbon fiber woven layer and orientation. In this study, variations of adjustment layers with 3 types of fiber orientation $\left(0^{\circ}, 45^{\circ}, 60^{\circ}\right)$. The result indicated that adding more carbon fiber layer could improve mechanical properties for sandwich beam.
\end{abstract}

Keywords-Balsa wood, Bending, Carbon fiber, Finite element, Torsional stiffness

\section{INTRODUCTION}

Nowadays, automotive and aerospace industries are developing rapidly. As the industries development is growing, we need more efficient performance of the engine. Engine efficiency can be increased by reducing energy consumption. Energy consumption could be reduce by improving the engine itself or reducing the body mass. One way to reduce the body mass is by replacing the material of chassis from metal to composite due to their high stiffness-to-weight and strength-to-weight ratios. Replacing the material from metal to composite will also reducing the production price up to $50 \%$.

Composite sandwich is one of the composite structure's types consisting of two flat composites, usually made of metal sheets or composite laminates, and cores. The purpose of using composites is to obtain better mechanical properties than its constituent materials. Sandwich structures have been successfully applied in aircraft structures, ship and train hulls, and wind turbine rotor blades. So far, the material used as core still has a high price and not environmentally friendly such as polyurethane, PVC foam, and honeycomb.

Wood is one of the structural materials that most being used because it is natural, renewable, biodegradable, inexpensive, have excellent axial stiffness to weight ratio, and have excellent strength to weight ratio. The core from natural origin is being developed, such as balsa (Ochroma pyramidale) wood. Balsa is mostly found in tropical areas, it has low density and the lightest wood did exist in the world, increasing the density will increase shear stiffness and strength of balsa wood ${ }^{1}$. Balsa sandwich composites have the same advantages as other sandwich composites, namely ultra-low weight and considerable stiffness, making it competitive alternative core material.

The previous research about comparison between impact responses and damage mechanisms of sandwich composites with two different cores, balsa wood and PVC foam, which are being used for the similar purposes in the structures presents that balsa wood has a higher stiffness than PVC foam in the same density ${ }^{2}$. The toughness of balsa is lower than most woods, but closer to other woods they previously expected considering its very low density ${ }^{3}$.The other properties of balsa wood such as compression strength, impact strength, toughness, and bending has been explained in the research before. Balsa wood is already popular for being used as an aeromodelling material but with those properties, balsa wood is the right material to use as a core in sandwich composite.

Reinforced divided into two types, particle reinforced and fiber reinforced. Glass fiber is the most common material that used to make a composite. But, another material with excellent properties that could be used as a reinforced is carbon fiber. The composite behavior under tension and compression in the fibers direction of unidirectional and continuous carbon fiber-reinforced epoxy has been evaluated before ${ }^{4}$. Carbon fiber has density five times smaller and tensile strength ten times higher than the conventional high-strength steels ${ }^{5}$.

Based on all the research before about balsa wood and carbon fiber, in 2014 there were a research about crack pattern in carbon fiber and balsa wood sandwich composite that happens depends on the number of impact. The number of ballistic limit indicating that it was capable of withstanding impacts from small projectiles such as, secondary debris from blast, hurricane, tornado and foreign object debris from roads and runways ${ }^{6}$.The example of application carbon fiber and balsa wood composite sandwich is for ladder chassis of vehicle, blades in turbine, and part of plane or ship. There are only a few researches about carbon fiber and balsa wood sandwich composite. In this paper, mechanical performance of the sandwich structure is studied by threepoint bending test and torsional test using finite element analysis software. The contributions of the research is that it can be used as a reference in the design of composite sandwich chassis and allow further development in the future

The organisation of the paper is the following. Section I introduces, in general terms, the outline of the work. Section II describes the properties of materials used in this research, the geometry of the specimens, and testing methods. Section III shows the result of simulation and analytical description of bending test and torsional test considering the different behaviour of the different number of layers composite and the different fiber orientation. Finally, Section IV gives the conclusions of the research. 


\section{METHOD}

\section{A. Materials}

Sandwich composite materials in this experiment are epoxy resin as a matrix, carbon fiber woven Wet $230 \mathrm{GPa}$ as the skin or reinforced, balsa wood as a core material, and additional material such as epoxy glue.

\section{1) Balsa wood}

The following properties of balsa wood used for the sandwich composite are shown in Table 1.

TABLE 1.

PROPERTIES OF BALSA WOOD

\begin{tabular}{ccc}
\hline \hline Property & Value & Unit \\
Density & 129.75 & $\mathrm{Kg} / \mathrm{m}^{3}$ \\
Young's Modulus & 3000 & $\mathrm{Mpa}$ \\
Poisson's Ratio & 0.38 & - \\
Shear Modulus & 230 & $\mathrm{Mpa}$ \\
Tensile Strength & 14 & $\mathrm{Mpa}$ \\
Compressive Strength & 7 & $\mathrm{Mpa}$ \\
Thermal Conductivity & 0.1 & $\mathrm{~W} / \mathrm{m}-\mathrm{K}$ \\
\hline \hline
\end{tabular}

\section{2) Carbon fiber}

Carbon fiber are fibers about 5-10 micrometers in diameter and composed mostly of carbon atoms. To produce a carbon fiber, the carbon atoms are bonded together in crystals that are more or less aligned in parallel to the long axis of the fiber as the crystals alignment gives the fiber high strength-to-volume ratio (making it strong for its size). Several thousand carbon fiber are bundled together to form a tow, which may be used by itself or woven into a fabric. The thickness of carbon fiber in this simulation is $0.5 \mathrm{~mm}$ for one layer. The following properties of carbon fiber and epoxy resin used for the sandwich composite are shown in Table 2 and Table 3.

TABLE 2.

PROPERTIES OF EPOXY CARBON WOVEN 230 GPA WET

\begin{tabular}{llc}
\hline \hline \multicolumn{1}{c}{ Property } & \multicolumn{1}{c}{ Value } & Unit \\
\hline Density & 1451 & $\mathrm{Kg} / \mathrm{m}^{3}$ \\
Young's Modulus X Direction & 59160 & $\mathrm{Mpa}$ \\
Young's Modulus Y Direction & 59160 & $\mathrm{Mpa}$ \\
Young's Modulus Z Direction & 7500 & $\mathrm{Mpa}$ \\
Poisson's Ratio XY & 0,04 & - \\
Poisson's Ratio YZ & 0.3 & - \\
Poisson's Ratio XZ & 0.3 & - \\
Shear Modulus XY & 17500 & $\mathrm{Mpa}$ \\
Shear Modulus YZ & 2700 & $\mathrm{Mpa}$ \\
Shear Modulus XZ & 2700 & $\mathrm{Mpa}$ \\
Tensile X Direction & 513 & $\mathrm{Mpa}$ \\
Tensile Y Direction & 513 & $\mathrm{Mpa}$ \\
Tensile Z Direction & 50 & $\mathrm{Mpa}$ \\
Compressive X Direction & -437 & $\mathrm{Mpa}$ \\
Compressive Y Direction & -437 & $\mathrm{Mpa}$ \\
Compressive Z Direction & -150 & $\mathrm{Mpa}$ \\
Shear XY & 120 & $\mathrm{Mpa}$ \\
Shear YZ & 55 & $\mathrm{Mpa}$ \\
Shear XZ & 55 & $\mathrm{Mpa}$ \\
\hline \hline
\end{tabular}

TABLE 3.

PROPERTIES OF EPOXY RESIN

\begin{tabular}{lcc}
\hline \multicolumn{1}{c}{ Property } & Value & Unit \\
\hline Density & 1200 & $\mathrm{Kg} / \mathrm{m}^{3}$ \\
Young's Modulus & 3780 & $\mathrm{Mpa}$ \\
Tensile Yield Strength & 54.6 & $\mathrm{~Pa}$ \\
\hline \hline
\end{tabular}

\section{B. Specimen design}

In order to proceed simulation with this study, the 3D model of the specimen dimension is $100 \mathrm{~mm} \times 50 \mathrm{~mm} \times$
$537 \mathrm{~mm}$. Sandwich panels were then made from carbon fiber face sheets on all sides of the balsa wood core, as illustrated in Figure 1.

This simulation consists of several stages:

1. Determination of Geometry Process

2. Modelling Process

3. Input Material

4. Running Process

Specimen geometry that has been design using 3D CAD software is imported into the finite element software. For the case of composite simulation with carbon fiber as reinforced with balsa wood as core, the geometry must form in the surface mode for the process of preparing the composite materials.

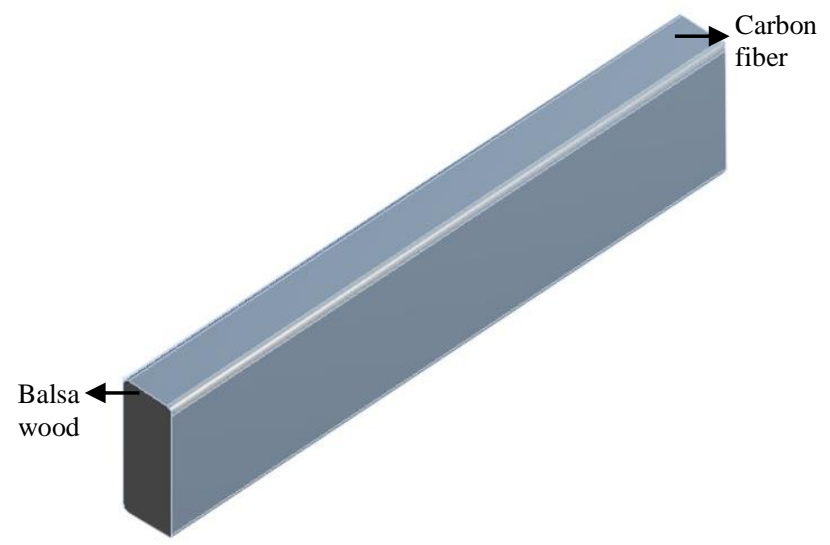

Figure 1. Assembly of Carbon Fiber and Balsa Wood Sandwich Composite.

To obtain the optimal result in the use of composite sandwich, the laying direction of the lamina is one of the factors that affecting the characteristics of sandwich composite. This simulation use static structural analysis (ACP) for composite. Before we run the simulation, we have to do the modelling process. In this process consist of setting the materials, thickness of the geometry, meshing, connections, and setting the desired conditions. Setting the condition for static structural is to determine the fix support area and the number of loads applied. From this setting, we would know the weight of specimen. The number of elements for meshing process in this specimen is 92784 . The meshing process for composite sandwich specimen is shown in Figure 2.

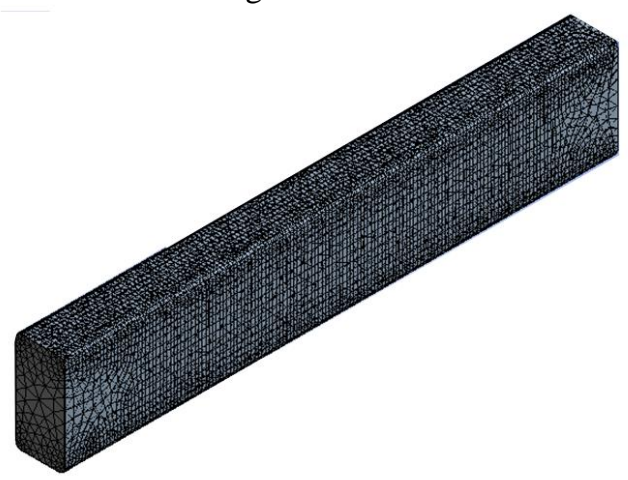

Figure 2. Meshing for Composite Sandwich Specimen

The next process after modelling process is setting for input materials. This process consist of input the material properties such as carbon woven $230 \mathrm{GPa}$ Wet for skin and balsa wood for core, setting the number of layers, 
setting the layers direction, and setting the fiber orientation.

In this numerical analysis, the specimen has three variants of fiber orientation and six variants of layers. The variants of layers are 1 layer, 2 layers, 3 layers, 5 layers, 7 layers, and 10 layers. Variants of fiber orientation are shown in Figure 3, there are $0^{\circ}$ fiber orientation, $45^{\circ}$ fiber orientation, and $60^{\circ}$ fiber orientation. Each specimen simulated in this finite element analysis software using unidirectional of fiber orientation. The results in this simulation are total deformation in millimeters from bending test and torsional test.
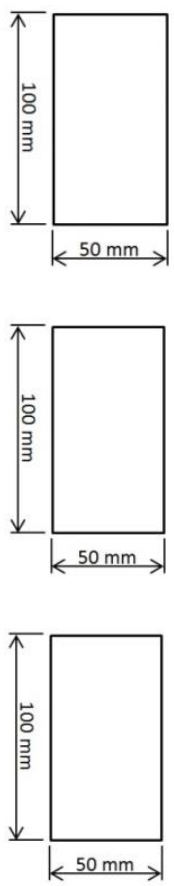

Figure 3. (a) Layout of $0^{\circ}$ Fiber Orientation. (b) Layout of $45^{\circ}$ Fiber Orientation. (c) Layout of $60^{\circ}$ Fiber Orientation

\section{Loading condition}

\section{1) Bending test}

Stress distribution of sandwich structure was analyzed using finite element analysis software. In this analysis, static force is applied as loads on the specimen. Three point bending test is shown on Figure 4 with support are given at each edge of the specimen.

Three point bending test is a classical flexural experiment in mechanics, used to obtained the mechanical characteristics of materials. It will determine the flexural stiffness of the composite. Ideally, the specimen would fail to crack (fracture) due to shear loads. At the top of the specimen receiving compression force due to load given by the machine and at the bottom of the specimen receiving tensile loads due to deflection occurs after the composite receive the load. In this test, force applied at center of upper side of the specimen is $9807 \mathrm{~N}^{7}$

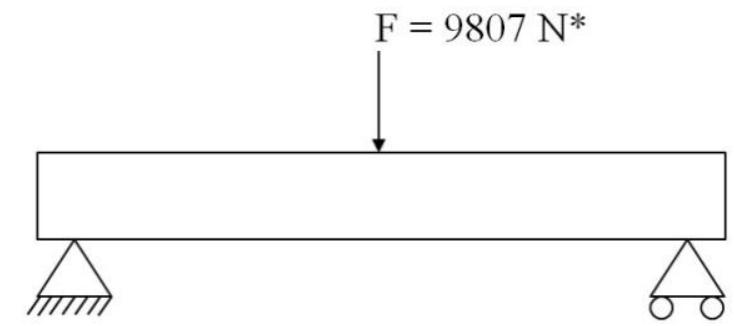

Figure 4. Specimen model for three point bending test

\section{2) Torsional test}

Rigidity against torque loads are regarded as the most important thing during the manufacture of chassis. The twisting force of a torsion test is applied to the test sample by anchoring one end so that it cannot move or rotate and applying a moment to the other end so that tha sample is rotated about its axis. Torsional test is to determine the behavior a material or test sample exhibits when twisted or under torsional forces as a result applied moments that cause shear stress about the axis. The sketch of this simulation is shown in Figure 5 that fixed support is given at one side of the specimen and force applied as a moment at the other side of specimen is 2633,2 N.m. The equation to determine moment that given in this simulation is:

$T=F \times d$

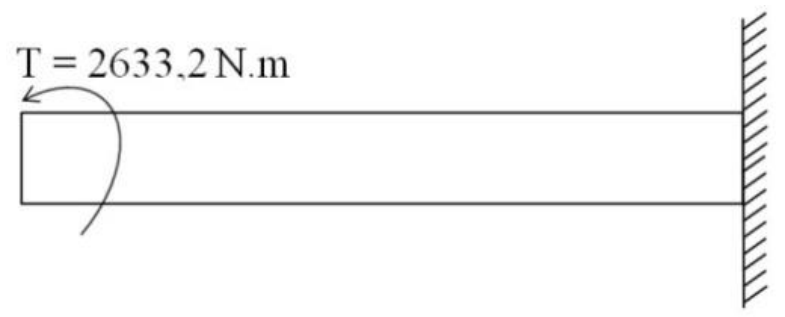

Figure 5. Specimen model for torsional test

\section{Torsional stiffness}

Torsional stiffness is the rigidity of an object to which it resists deformation in response to an applied torsional force. The value of stiffness of each car is different and there is no standard that would limit the value of the minimum stiffness of car. That is based on the dimension, weight, and type of material.

The result of this simulation for torsional test is total deformation and stress distribution. From that result, the equation to determine torsional stiffness of vehicle in this simulation is:

$K=\frac{T}{\theta}$

$\theta=\tan ^{-1}\left(\frac{z_{1}+z_{2}}{2 b}\right)$

$K=\frac{F \times d}{\tan ^{-1}\left(\frac{z_{1}+z_{2}}{2 b}\right)}$

Where, $\mathrm{K}$ is torsional stiffness $(\mathrm{Nm} / \mathrm{deg}), \mathrm{T}$ is moment $(\mathrm{Nm}), \mathrm{F}$ is vertical force $(\mathrm{N}), \mathrm{d}$ is half of the length of specimen, $\mathrm{z}_{1}$ is vertical deflection $1(\mathrm{~m}), \mathrm{z}_{2}$ is vertical deflection $2(\mathrm{~m}), \theta$ is angle deflection (deg), and $b$ is the width of specimen.

\section{RESULT AND ANALYSIS}

\section{A. Static structural analysis for bending test}

From Figure 6, it is observed that the maximum total deformation obtained from the simulation is at the center of the specimen with red area color. The total deformation decrease as the area further away from the center of the specimen. The distribution area of total deformation that happens in the specimen is similar to the 1 layer sandwich composite to 10 layers sandwich composite.

Result for total deformation in bending test and the effect from adjust layers and fiber orientation variations to total deformation in this simulation are shown in Figure 9 as a graphic. The minimum total deformation is 0.087 $\mathrm{mm}$, it is occurs in sandwich composite with 10 layers and $60^{\circ}$ of fiber orientation and the maximum total 
deformation is $0.309 \mathrm{~mm}$, it is occurs in sandwich composite with 1 layers and $45^{\circ}$ of fiber orientation.

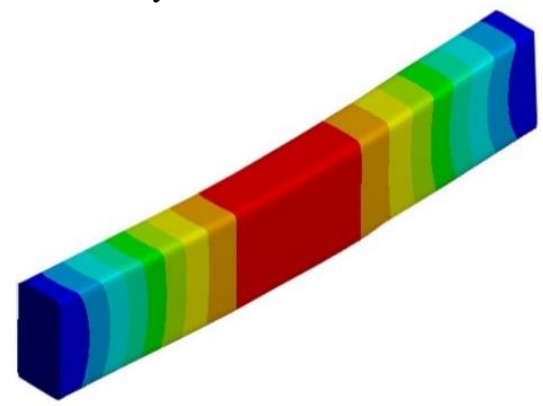

Figure 6. Total deformation for bending test 1 layer

From Figure 9, shows graphic of total deformation that happens against the layers of composite with three variants of fiber orientation and six variants of layers. It is obtained that increasing of layers will decrease the total deformation that happens to the composite.

B. Static structural analysis for torsional test

From Figure 7, it is observed that the maximum total deformation obtained from the simulation is at the reverse side from the fixed support of the specimen and further away from the core, it is mentioned at the software with red area color. The total deformation decrease as the getting closer to the center of the axis specimen, it is mentioned by orange until dark blue area color in the software. The distribution area of total deformation that happens in the specimen is similar to the 1 layer sandwich composite to 10 layers sandwich composite.

In this simulation, the result is total deformation and will be analyzed with equation 2 to found the torsional stiffness of this specimen. Result for the torsional test in this simulation can be in Figure 10 as a graphic.

The minimum torsional stiffness is $753.02 \mathrm{Nm} / \mathrm{deg}$, it is occurs in sandwich composite with 1 layers and $0^{\circ}$ of fiber orientation and the maximum torsional stiffness is $5058.21 \mathrm{Nm} / \mathrm{deg}$, it is occurs in sandwich composite with 10 layers and $45^{\circ}$ of fiber orientation.

In this simulation, the result is total deformation and will be analyzed with equation 2 to found the torsional stiffness of this specimen. Result for the torsional test in this simulation can be in Figure 10 as a graphic.

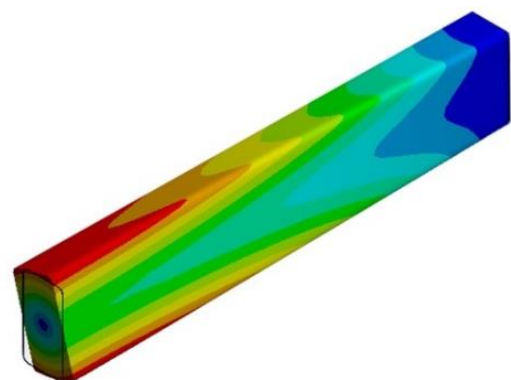

Figure 7. Total deformation for torsional test 1 layer

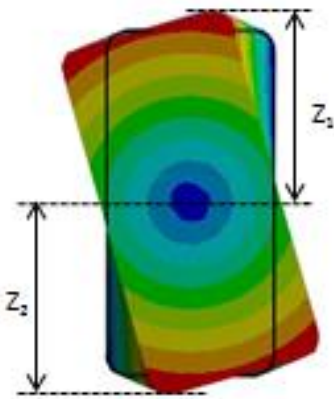

Figure 8. Front view of total deformation for torsional test 1 layer

From Figure 10, shows graphic of torsional stiffness that happens against the layers of composite with three variants of fiber orientation and six variants of layers similar to that are used in bending test before. It is obtained that increasing of layers will increase the torsional stiffness that happens to the composite. The specimen with $45^{\circ}$ of fiber orientation have the highest torsional stiffness in every layer of sandwich composite and the specimen with $0^{\circ}$ of fiber orientation have the lowest torsional stiffness in every layer of sandwich composite.



Figure 9. Total Deformation - Layers Curve 


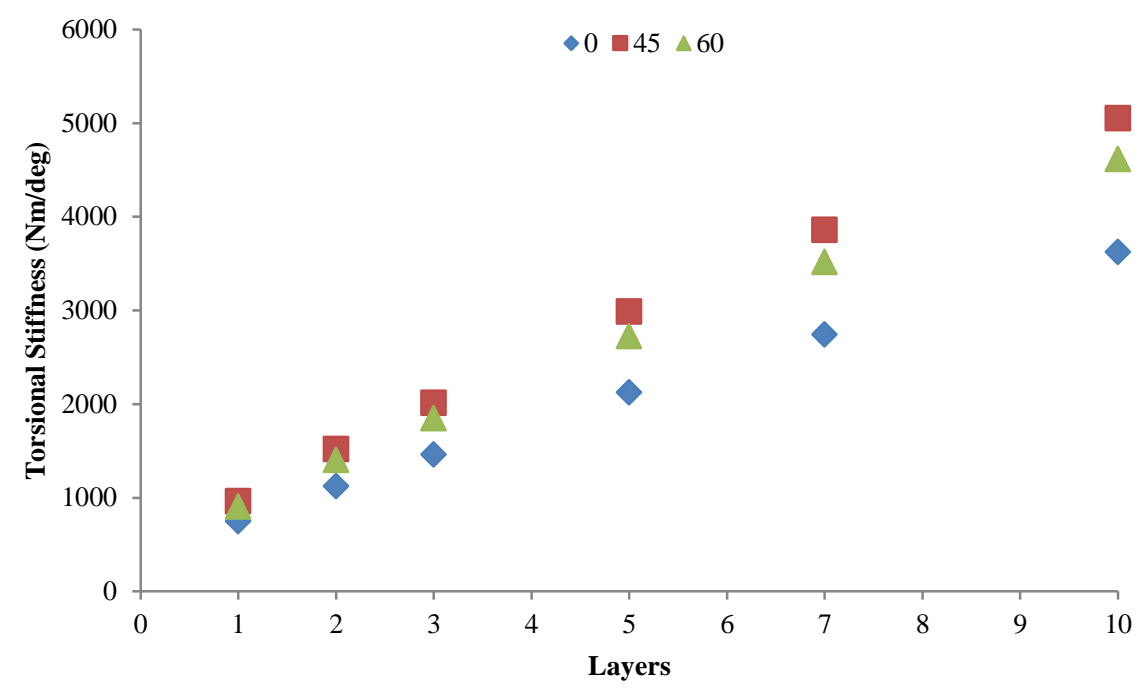

Figure 10. Torsional Stiffness - Layers Curve

\section{CONCLUSION}

Sandwich composite with $60^{\circ}$ fiber orientation have the lowest value $(0.087 \mathrm{~mm})$ of total deformation than the other fiber orientation variations. However, sandwich composite with $45^{\circ}$ fiber orientation have the highest value $(5058.21 \mathrm{Nm} / \mathrm{deg})$ of torsional stiffness than the others. From the above results, it can be seen that adjust of carbon fiber layers can decreased total deformation and increased torsional stiffness of the specimen. If focus on deformation, the best material is sandwich composite with $0^{\circ}$ of fiber orientation. But if focus on the stiffness, the best material is sandwich composite with $45^{\circ}$ of fiber orientation

\section{REFERENCES}

[1] Antwi, Michael Osei. Et al., Analytical modelling of local stresses at balsa/timber core joints of FRP sandwich structures. Switzerland. 2014.
[2] Atas, Cesim\&Cenk Sevim, On the impact response of sandwich composites with cores of balsa wood and PVC foam. Turkey. 2010.

[3] Mohammadi, Meisam Shir\&John A Nairn, Crack Propagation and Fracture Toughness of Solid Balsa Used for Cores of Sandwich Composites. Oregon State University. 2014.

[4] Uriya, Yu. Cold and warm V-bending test for carbon-fiberreinforced plastic sheet. Jepang. 2014.

[5] Moreno, M.C.Serna. et al., Different Response Under Tension and Compression of Unidirectional Carbon Fibre Laminates in Three-Point Bending Test. Spanyol. 2015.

[6] Jover, N. et al., Ballistic impact analysis of balsa core sandwich composites. United States. 2014

[7] Ismail, Static and Dynamic Analysis of a Ladder Frame Truck Chassis. Faculty of Mechnical Engineering Universiti Teknologi Malaysia, 2009. 